\title{
SYNTHESIS AND CHARACTERIZATION OF AN AMIDOXIME COMPOUND WITH BENZIMIDAZOLE MOIETY AND PH SENSING BEHAVIOR UNDER BASIC CONDITION IN METHANOL AND DMSO
}

\author{
MOHAMMAD NAHIDUR RAHMAN, *a RINA RANI BHOWMICK, ${ }^{a}$ MOHAMMAD NURNABI, ${ }^{a}$ \\ MD. ASHRAFUL ISLAM MOLLA
}

Department of Applied Chemistry and Chemical Engineering, University of Dhaka, Nilkhet Road, Dhaka-1000, Bangladesh

\begin{abstract}
An amidoxime containing 2-phenyl-1H-benzimidazole derivative, 4-(1H-Benzoimidazol-2-yl)-N-hydroxy-benzamidine, was synthesized by conversion of nitrile group of previously synthesized 2-(4-cyanophenyl)-1H-benzimidazole by treatment with hydroxylamine under alkaline solution. Characterization of both compounds was carried out by using UV-Vis, FT-IR, ${ }^{1} \mathrm{H}$ NMR and ${ }^{13} \mathrm{C}$ NMR, and mass spectroscopic technique. Its photophysical behavior was compared in methanol and DMSO under basic condition.
\end{abstract}

\section{INTRODUCTION}

Amidoxime group exhibited superior adsorption ability because it contains both amino and oxime groups that can form strong complexes with metal ions via the coordination reaction. ${ }^{1}$ Due to such chelating properties a number of resin containing amidoxime to extract heavy metals from various sources have been developed especially dealing with uranium recovery from sea water is being studied in many countries. ${ }^{2}$ Incorporation with various polymer such as acrylonitrile-divinyl benzene, ${ }^{3}$ cellulose, ${ }^{4}$ divinylbenzene cross-linked polymers ${ }^{5}$ of trace metals in natural waters. On the other hand, a number of resin have been developed for selective adsorption of various metals such as resin containing amidoxime-guanidine ${ }^{6}$ functional group for $\mathrm{Ag}(\mathrm{I})$, silica gel based hybrid material ${ }^{7}$ for $\mathrm{Hg}(\mathrm{II})$, composite chelating particles poly(amidoxime)silica ${ }^{8}$ and polyacrylonitrile (PAN) grafted sago starch $^{9}$ for $\mathrm{Cu}(\mathrm{II})$, silica gelbased sorbent ${ }^{10}$ for $\mathrm{Fe}(\mathrm{II})$, commercial amidoxine resin Duolite ES-346 ${ }^{11}$ for extraction of gallium, etc. Amidoximes, for example, succinediamidoxime, ${ }^{12}$ 3,5-dimethyl, 3-phenyl-5-methyl and 3,5-diphenyl-4-isoxazolylamidoxime, ${ }^{13}$ 3,5-dimethyl-4-isoxazolyl acetamidoxime, ${ }^{14}$ ethanediamidoxime, ${ }^{15}$ have showed interesting analytical applications. Meanwhile amidoximes are the valuable starting materials for the synthesis of various heterocyclic compounds and as well as useful building blocks for heteroarenes such as imidazoles, ${ }^{16}$ benzimidazoles, ${ }^{17}$ pyrimidines,${ }^{18}$ pyrazine, ${ }^{19}$ quinazoline ${ }^{20}$ etc.

On the other hand benzimidazole rings are known to be very reactive because of the trivalent imidazole nitrogen offers a site for functionalization of the compound. ${ }^{21} \mathrm{~A}$ large number of benzimidazole derivatives have been developed that have been found in medicinal chemistry applications include antibacterial and antifungal agents, ${ }^{22}$ anthelmintic agents, ${ }^{23}$ cytotoxic and antitumor agents, ${ }^{24}$ DNA binding agents ${ }^{25}$ etc. Moreover benzimidazole have been reported to use as organic ligands ${ }^{26}$ and fluorescent whitening agent dyes. ${ }^{27}$

Till now, synthesis of 2-phenylbenzimidazole derivative containing amidoxime using sodium methoxide has not been reported before. Current approach is to reveal a route of synthesis of a 2-phenylbenzimidazole derivative (compound 2) containing amidoxime and its characterization. Moreover, the $\mathrm{pH}$ effect on amidoxime functional groups in aqueous media has been found highly important ${ }^{28}$ to study the complexion of heavy metals especially uranium, ${ }^{29}$ vanadium. ${ }^{30}$ Extensive studies showed that only amidoxime groups can effectively extract uranium from seawater and $\mathrm{pH}$ plays an important role in complexion of uranium.

Herein we report to photophysical behavior of compound 2 under basic condition in non-aqueous media like methanol and DMSO.

\section{EXPERIMENTAL}

Materials

All of the chemicals used in this work were of analytical grade purchased from commercial suppliers and used without further purification. Organic compounds (4-cyanobenzaldehyde, phenyl-1, 2-diamine, sodium methoxide, hydroxylamine hydrochloride), organic solvents (methanol, ethanol, ethyl acetate, dimethyl sulfoxide) were used as obtained. 2-cyanomethylbenzimidazole was prepared using the procedure described previously in literature. ${ }^{31}$

General procedure of synthesis of 2-(4-cyanophenyl) benzimidazole 1

4-cyanobezaldehyde (1mmol) and phenyl-1, 2-diamine (1mmol) were dissolved in ethanol $4 \mathrm{ml}$. The solution was refluxed for $4 \mathrm{hrs}$. The solvent was then removed by distillation. The solid product was then purified by crystallization by ethanol.

FT-IR (KBr) $\mathrm{cm}^{-1}: 3440$ (-N-H stretch, imidazole), 2370 (-C $\equiv \mathrm{N}$ stretch, cyano), 1610 ( $\mathrm{C}=\mathrm{N}$ stretch, imidazole), 1370 (C-N stretch, imidazole $)$

${ }^{1} \mathrm{H}$ NMR (D O): 8.130(2H, d, J=17.52Hz, C2'-H, C6'-H) 7.793(2H, d, $\mathrm{J}=17.6 \mathrm{~Hz}, \mathrm{C} 3$ '-H, C5'-H), 7.537(2H, m, C4-H, C7-H), 7.200(2H, m, J=5.84Hz, C5-H, C6-H)

General procedure of synthesis of 4-(1H-Benzoimidazol-2-yl)-Nhydroxy-benzamidine 2

The compound $1(0.3 \mathrm{mmol})$ and hydroxylamine hydrochloride $(0.3 \mathrm{mmol})$ were dissolved in methanol $(3 \mathrm{ml})$ in the presence of sodium methoxide $(0.28 \mathrm{mmol})$. The solution was refluxed for $24 \mathrm{hrs}$. The reaction was monitored by TLC. The solvent was then removed by evaporation. The crude product was dissolved in ethyl acetate and filtered off. The filtrate was then dried and water was added. The precipitate was then removed by filtration. Further purification was carried out by crystallization in ethanol.

FT-IR (KBr) cm ${ }^{-1}: 3440$ (N-H stretch, imidazole), 1640 (C-N stretch, oxime), 1430 (C-N stretch, imidazole)

${ }^{1} \mathrm{H}$ NMR (D O): 8.399 $\left(2 \mathrm{H}, \mathrm{d}, \mathrm{J}=8.8 \mathrm{~Hz}, \mathrm{C} 2\right.$ '- $\left.\mathrm{H}, \mathrm{C} 6{ }^{\prime}-\mathrm{H}\right), 8.083(2 \mathrm{H}, \mathrm{d}$, $\mathrm{J}=8.4 \mathrm{~Hz}, \mathrm{C} 3$ ' $-\mathrm{H}, \mathrm{C}^{\prime}$ '-H), 7.892(2H, m, J=2.8Hz, C4-H, C7-H), 7.685(2H, m, $\mathrm{J}=3.2 \mathrm{~Hz}, \mathrm{C} 5-\mathrm{H}, \mathrm{C} 6-\mathrm{H})$

${ }^{13} \mathrm{C} \mathrm{NMR}\left(\mathrm{CDCl}_{3}\right): 163.191,139.341,130.646,129.996,129.187,128.411$, $115.376,103.499,79.137,79.077,74.406,49.698,49.489,49.275$

Mass spectrum (ES/MS): m/z 253

Analysis

Qualitative test of amidoxime functional group:

About $0.02 \mathrm{~g}$ of compound $\mathbf{2}$ was shaken with vanadium $(\mathrm{V})$ ion in dilute hydrochloric acid solution and a purple colored complex was observed.

Spectral Characterization

In order to characterize compound $\mathbf{1}$ and compound 2 FT-IR analysis was made. IR spectra were acquired on IR spectra were recorded on an IR Prestige 21 FT-IR instrument from Shimadzu corporation. FTIR spectra of these compounds were taken by mixing the compound (about $0.1 \mathrm{~g}$ ) thoroughly mixed with $\mathrm{KBr}(0.1 \mathrm{~g}$, IR grade, Merck, Germany), and pressed into a pellet from the spectrum was then recorded. UV-Vis absorption spectra were acquired using a UV-1700series spectrophotometer. UV-visible spectrophotometric investigations were performed at concentrations of $1.00 \times 10^{-4} \mathrm{M}$ compound 2. The stock solutions of the compounds $\left(1.00 \times 10^{-3} \mathrm{M}\right)$ were prepared in a $10 \mathrm{~mL}$ volumetric flask, by dissolving in methanol and diluting to the mark with methanol, and the required concentration then being obtained by accurate dilution. The stock solution of compound $\mathbf{2}$ and DMSO is prepared in similar manner. The base solutions of $1.0,0.1$, or $0.01 \mathrm{M}$ using sodium hydroxide were prepared. The effect of $\mathrm{pH}$ upon absorption intensity was examined by the addition of $1.0,0.1$, or $0.01 \mathrm{M}$ volumes of sodium hydroxide to $25 \mathrm{~mL}$ aliquot containing $1.0 \times 10^{-4} \mathrm{M}$ compound 2 in order to obtain neutral to alkaline $\mathrm{pH}$ values $^{32}$ in methanol. Each time the $\mathrm{pH}$ was checked by the $\mathrm{pH}$ meter. In case of DMSO, same amount of sodium hydroxide was added. UV/vis absorption spectra were recorded for each one. NMR and ${ }^{13} \mathrm{C}$ NMR spectra were recorded in $\mathrm{CDCl}_{3}$ on a Bruker - $400 \mathrm{MHz}$ NMR spectrometer with TMS as internal standard. Mass spectra were obtained on a Bruker $400 \mathrm{MHz}$ spectrometer. TLC was performed by using chromatographic plate from Eastman Kodak Co. USA. Distilled water was obtained from Barnstead Fistreemll water distillation unit; model A74410 from Sanyo Gallenkamp PLC, UK. 


\section{RESULT \& DISCUSSION}

Synthesis of the compound $1 \& 2$ :

The compound 1 was prepared from 4-cyanobenzaldehyde and 1, 2-phenylenendiamine in ethanol using air as oxidant under reflux (Scheme 1). The purification process involved the removal of solvent via rotary evaporator.
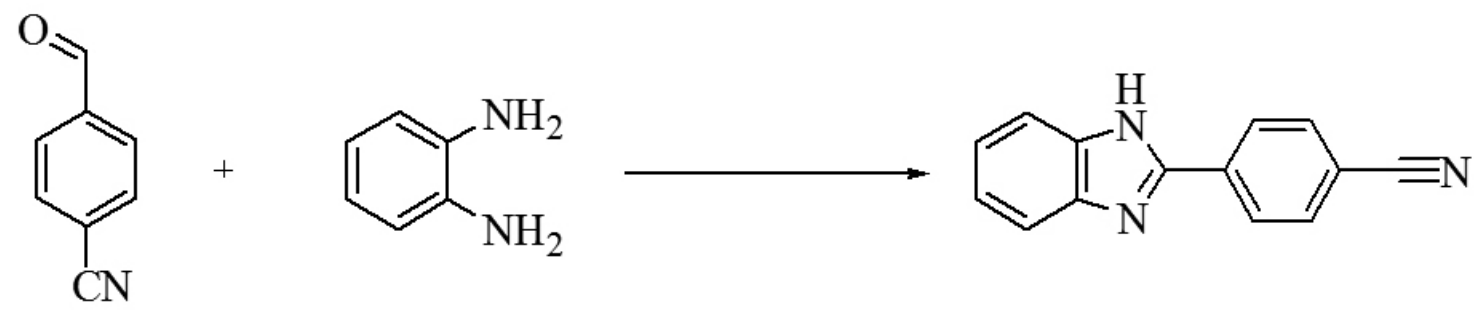

1

Scheme 1: Synthesis of 4-(1H-Benzoimidazol-2-yl)-benzonitrile 1 from 4-formyl-benzonitrile and benzene-1,2-diamine.

The compound $\mathbf{2}$ was prepared from compound $\mathbf{1}$ that reacts with hydroxylamine hydrochloride in the presence of sodium methoxide in ethanol under reflux. The crude product was dried and dissolved in ethyl acetate and filtered. The filtrate was dried to give crude product. The dried crude was washed with water to remove the excess starting materials and any byproduct that dissolve in water. Further purification was carried out by recrystallization from ethanol. The completion of the reaction and the purity of the product were monitored by TLC. The compound remains at the top of the chromatogram in the hexane-ethylacetate (30:70) solvent system. The reaction was carried out in acidic condition where in cyano group of compound $\mathbf{1}$ underwent protonation and then nucleophilic attack at C-atom of cyano group gave the final product (Scheme 2)<smiles>N#Cc1ccc(-c2nc3ccccc3[nH]2)cc1</smiles>

1

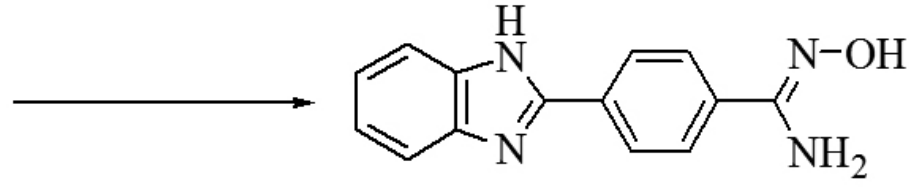

2

Scheme 2: Synthetic route to amidoxime derivative.

Qualitative test of amidoxime functional groups:

Presence of amidoxime groups in the resin was confirmed by several methods of which vanadium ion test was employed in most case..$^{33}$ Here the amidoxime groups in the synthesized compound $\mathbf{2}$ formed complex with vanadium that was confirmed by purple color.

Spectral Characterization of compound $1 \& 2$ :

The structures of the compounds were elucidated by spectral data analysis. The IR spectra of the compounds were consistent with the structures assigned to them. The IR spectrum of compound 1 showed the characteristic C-N stretching absorption band for cyano group at $2370 \mathrm{~cm}^{-1}$. The board band at $3400 \mathrm{~cm}^{-1}$ was assigned to $\mathrm{N}-\mathrm{H}$ stretching. The band at $1610 \mathrm{~cm}^{-1}$ was attributed to the $-\mathrm{C}-\mathrm{N}$ stretching of the imidazole ring. The IR spectrum of compound $\mathbf{2}$ showed the characteristic absorption band at about $3440 \mathrm{~cm}^{-1}$ assigned to N-H stretching. There should be a broad absorption bands observed at about 3400 $\mathrm{cm}^{-1}$ attributed to the stretching vibration of -OH group of amidoxime that was overlapped by the board band due to $\mathrm{N}-\mathrm{H}$ stretching. The band at $1640 \mathrm{~cm}^{-1}$ was attributed to $-\mathrm{C}-\mathrm{N}$ stretching of the oxime group and at about $1680 \mathrm{~cm}^{-1}$ that of imidazole ring that was also overlapped. The characteristic absorption of compound 1 at $2370 \mathrm{~cm}^{-1}$ due to $\mathrm{C} \equiv \mathrm{N}$ stretching was disappeared after amidoxime group preparation as found in Figure 1.

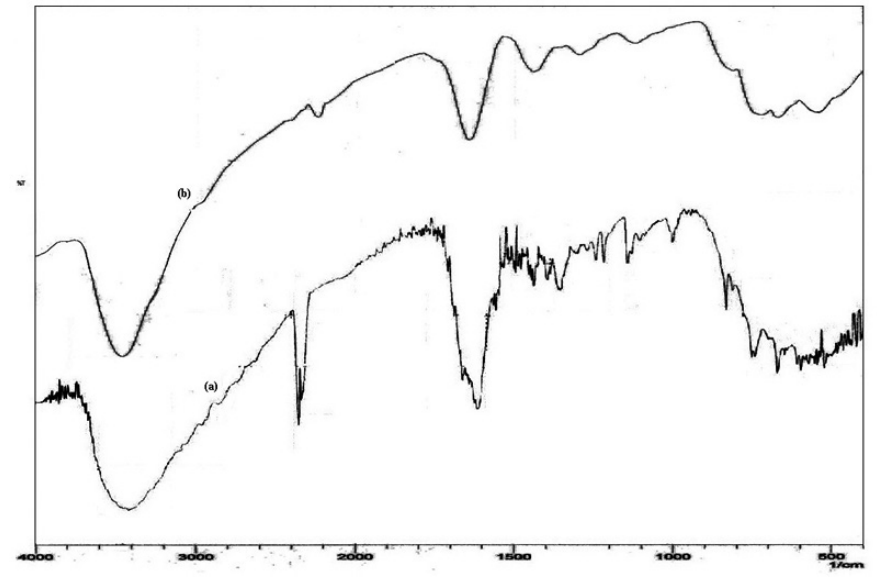

Figure 1: IR spectra of compounds 1 (a) and 2 (b).

In the $\mathrm{H}^{1}$-NMR spectra for compound 2 , the peaks of aromatic protons of the phenyl ring attached at 2-position of benzimidazole ring were observed about $8.38-8.41 \mathrm{ppm}$ and $8.07-8.09 \mathrm{ppm}$ as doublets and that of the phenyl ring attached to the imidazole ring were observed about $7.65-7.86 \mathrm{ppm}$ and 7.70 $7.92 \mathrm{ppm}$ as multiplets. The peaks of $\mathrm{N}-\mathrm{H}$ protons of the imidazole ring were disappeared in the spectrum due to the exchange of proton at $\mathrm{N}$ with deuterium present in solvent.

Spectral behavior of compound 2 in different media

The electronic spectra of compound $\mathbf{2}$ in methanol and DMSO were recorded in basic conditions. The band maxima, the absorption bands appearing in the spectra of the studied compounds at different $\mathrm{pH}$ in methanol and due to addition of same amount of $\mathrm{NaOH}$ in DMSO that used in methanol, are 
compiled in Tables 1 ( $\mathrm{a} \& \mathrm{~b}$ ). The electronic absorption spectra of the studied compounds have been recorded in methanolic solutions of varying $\mathrm{pH}$ ranging from 7.0 to 13.0 .

In methanolic solutions of $\mathrm{pH}$ ranging from 7 to 11 , the visible spectra of the compounds comprise one main band with max of $\mathbf{3 1 4} \mathrm{nm}$ while its intensity decreases by increasing the $\mathrm{pH}$ value which represents the spectra of neutral form. In the solutions of $\mathrm{pH}>11.0$, band is shift at longer wavelengths with the decrease in intensity by increasing the $\mathrm{pH}$ value, where in higher $\mathrm{pH}$ media $(\mathrm{pH}$ $=13$ ), the $\lambda_{\text {max }}$ of the band reaches to $328 \mathrm{~nm}$. This behavior can be attributed to ionization of $\mathrm{O}-\mathrm{H}$ group of the benzene ring. The recorded spectrum in the $\mathrm{pH}$ 11 represents the absorption of the deprotonated form of the compounds that takes place at the oxygen atom of the hydroxyl group of the benzene ring. Thus, a clear isosbestic point is observed in the $\mathrm{pH}$ range $11-13$, which indicates the presence of anion-neutral equilibrium as represented below:<smiles>N/C(=N\O)c1ccc(-c2nc3ccccc3[nH]2)cc1</smiles>

3

Scheme 3: Anion-neutral equilibrium.

Table 1a: UV absorbance of Compound $\mathbf{2}$ at different $\mathrm{pH}$ in Methanol.

\begin{tabular}{|c|c|c|c|}
\hline \multirow{2}{*}{ Entry No } & \multirow{2}{*}{$\mathrm{pH}^{\mathrm{a}}$} & $\lambda_{\max }$ & \multirow{2}{*}{ Absorbance } \\
\cline { 3 - 3 } & & $\mathrm{nm}$ & 1.601 \\
\hline 1 & 7 & 314 & 2.647 \\
\hline 2 & 8 & 314 & 2.581 \\
\hline 3 & 9 & 313 & 2.436 \\
\hline 4 & 10 & 315 & 2.275 \\
\hline 5 & 11 & 316 & 2.063 \\
\hline 6 & 12 & 317 & 1.982 \\
\hline 7 & 13 & 328 & \\
\hline
\end{tabular}

${ }^{\text {a }}$ calculated as $\mathrm{pH}=14+\log [\mathrm{NaOH}]$

Table 1b: UV absorbance of Compound $\mathbf{2}$ at same concentration of $\mathrm{NaOH}$ added in DMSO.

\begin{tabular}{|c|c|c|c|}
\hline \multirow{2}{*}{ Entry No } & \multirow{2}{*}{$\mathrm{pH}^{\mathrm{a}}$} & $\lambda_{\max }{ }^{\mathrm{b}}$ & \multirow{2}{*}{ Absorbance } \\
\cline { 3 - 4 } & & $\mathrm{nm}$ & 1.346 \\
\hline 1 & 7 & 321 & 1.354 \\
\hline 2 & 8 & 320 & 1.380 \\
\hline 3 & 9 & 321 & 1.392 \\
\hline 4 & 10 & 321 & 1.511 \\
\hline 5 & 10.3 & 332 & 1.681 \\
\hline 6 & 10.6 & 341 & 1.860 \\
\hline 7 & 11 & 351 & 1.806 \\
\hline 8 & 12 & 352 & 1.799 \\
\hline 9 & 13 & 352 & \\
\hline
\end{tabular}

${ }^{\mathrm{b}} \lambda_{\text {max }}$ measured due to addition of same amount of $\mathrm{NaOH}$ as in case of in $\mathrm{MeOH}$

In DMSO solutions were added with same amount of $\mathrm{NaOH}$ solution as done in case of methanolic solution to find out the effect of same amount of $\mathrm{OH}^{-}$ions in different solvent in different polarities.

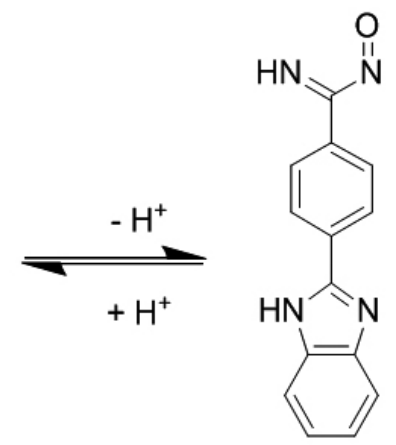

5
4 $\overbrace{}^{\circ}$<smiles>N=C(N)c1ccc(-c2nc3ccccc3[nH]2)cc1</smiles> 
compound comprises one main band with $\lambda_{\text {max }} 321 \mathrm{~nm}$ hence there was a red shift in $\lambda_{\max }$ (about $7 \mathrm{~nm}$ ) with the increase of the solvent polarity.

This behavior indicates that the excited state of compound $\mathbf{2}$ is more polar than their ground state and, thus, this red shift stabilizes the excited state more than the ground state as the polarity of the solvent increased. In that case, the separation between the ground and excited state energies is decreased, i.e., lower excitation energy is required in DMSO relative to $\mathrm{MeOH} .{ }^{34}$

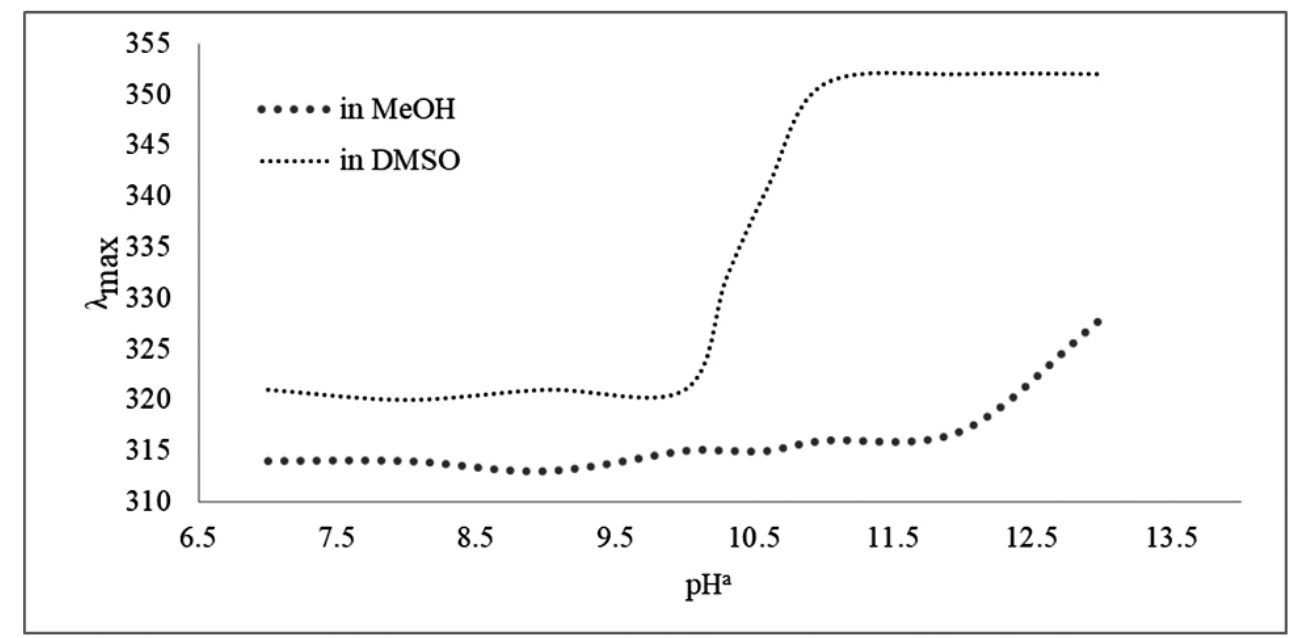

Figure 3: Shifting to longer wavelenth $\left(\lambda_{\max }\right)$ with the increase of basicity.

On the other hand, in DMSO, the band is shift at longer wavelengths with the increase in intensity by increasing the basicity of the solution and the $\lambda_{\max }$ of the band reached to $352 \mathrm{~nm}$ (Figure 3). The red shift (by about $31 \mathrm{~nm}$ ) in case of DMSO is significantly higher than that in methanol (by $14 \mathrm{~nm}$ ) that is almos double. It can be concluded that the deprotonation in more polar solvent results in higher stability of the conjugation system than in less polar one.

\section{CONCLUSION}

It is recent that synthesis of benzimidazole containing amidoxime functional group has been established. Spectroscopical study of amidoximes in different $\mathrm{pH}$ and solvents is still an interesting scope of investigation and not reported in literature quite enough. Herein, we synthesized compound 2 that was characterized by IR, NMR and mass spectroscopy. We have found that amidoxime group of the compound $\mathbf{2}$ showed good $\mathrm{pH}$ sensing properties in methanol and DMSO. Moreover, in higher basic conditions compound 2 shows a considerable red shift (by about $31 \mathrm{~nm}$ ) in DMSO. Hence, our study reveals a means of further studies spectroscopically considering acidic and basic conditions as well as the choice of solvents.

\section{REFERENCE}

1. A. B. Goel, V. D. Gupta, J. Organomet. Chem. 72, 171, (1974)

2. (a) H. Egawa, M.Nakayama, T. Nonaka, E. Sugihara, J. Appl. Polym. Sci. 33, 1993, (1987), (b) H. Egawa, T. Nonaka, S. Abe, M. Nakayama, J.Appl. Polym. Sci. 45, 837, (1992), (c) N. Kabay, H. Egawa, J. Appl. Polym. Sci. 51, 381, (1994), (d) N. Kabay, T. Hayashi, A. Jyo, H. Egawa, J. Appl. Polym.Sci. 54, 333, (1994), (e) Y. Zhaoa, J. Lib, L. Zhaod, S. Zhanga, Y. Huanga, X. Wua, X. Wanga, Chem. Eng. J. 235, 275, (2014)

3. H. Egawa, N. Kabay, T. Shuto, A. Jyo, J. Appl. Polym.Sci. 46, 129, (1992)

4. H. Kubota and Y. Shigehisa, J. Appl. Polym. Sci. 56, 147, (1995)

5. A. Nilchia, A. A. Babaloub, R. Rafieeb, H. Sid Kalala, React. Funct. Polym. 68, 1663, (2008)

6. Y. Wang, X. Ma, Y. Li, , X. Li, L. Yang, L. Ji, Y. He, Chem. Eng. J. 209, 394, (2012)

7. (a) R. Qua, Y. Zhanga, W. Qub, C. Suna, J. Chena, Y. Pinga, H. Chena, Y. Niua, Chem. Eng. J. 219, 51, (2013), (b) J. Chen, R. Qu, Y. Zhang, C. Sun, C. Wang, C. Ji, P. Yin, H. Chen, Y. Niu, Chem. Eng. J. 209, 235, (2012)

8. B. Gao, , Y. Gao, Y. Li, Chem. Eng. J. 158, 542, (2010)

9. M. R. Lutfor, S. Silong, W. M. Zin, M.Z. Ab Rahman, M. Ahmad, J. Haron, Euro. Polym. J. 36, 2105, (2000)

10. I. N. Voloschik, M. L. Litvina, B. A. Rudenko, J. Chromatogr. A 671, 51, (1994)

11. P. A. Riveros, Hydrometallurgy 25, 1, (1990)
12. J. L. Bernal, M. J. del Nozal, L. Debán, J. L. del Valle, V. Cerdá, J. M. Estela, J. Thermal Anal. 31, 931, (1986)

13. J. L. Bernal, M. Pedrero, V. Cerdá, J. Cantallops, Thermochim. Acta. 98 19, (1986)

14. J. L. Bernal, M. J. Del Nozal, L. Debán, B. Nuñez, V. Cerdá, J. M. Estela, Thermochim. Acta. 103, 259, (1986)

15. R. Jara, V. Cerdá, Thermochimic. Acta. 142, 135, (1989)

16. M. Guillemet, A. Robert, M. Baudy-Floc'h, Tetrahedron Lett., 36, 547 (1995)

17. C. A. Ramsden, H. L. Rose, J. Chem. Soc., Perkin Trans.1, 615, (1995)

18. A. Y. Il'chenko, V. I. Krokhtyak, L. M. Yagupol'skii, Chem. Heterocycl. Compd. 17, 1236, (1981)

19. K. Gobis, H. Foks, A. Kedzia, M. Wierzchowska, E. Kwapisz, Z. Zwolska, E. Augustynowicz-Kopec, Acta Pol Pharm. 63,39, (2006)

20. W. Szczepankiewicz, J. Suwi'nski, R. Bujok: Tetrahedron 56, 9343, (2000)

21. E. M. Cross, K. M. White, R. S. Moshrefzadeh, C.V. Francis, Macromolecules 28, 2526, (1995)

22. K. G. Desai, K. R. Desai, Bioorg. Med. Chem. 14, 8271-8279, (2006)

23. A. T. Mavrova, K. K. Anichina, D. I. Vuchev, J. A. Tsenov, P. S. Denkova, M. S. Kondeva, M. K. Micheva, Eur. J. Med. Chem. 41, 1412-1420, (2006)

24. A. K. Singh, J. W. Lown, Anticancer Drug Des. 15, 265-275, (2000)

25. P. Chaudhuri, B. Ganguly, S. Bhattacharya, J. Org. Chem. 72, 1912-1923, (2007)

26. P. Hao, S. Zhang, W. -H. Sun, Q. Shi, S. Adewuyi, X. Lu, P. Li, Organometallics 26, 2439-2446, (2007)

27. D. D. Rajadhyaksha, D. W. Rangnekar, J. Chem. Technol. Biotechnol. 36, 300-304, (1986)

28. (a) N. Mehio, M. A. Lashely, J. W. Nugent, L. Tucker, B. Correia, C. L. Do-Thanh, S. Dai, R. D. Hancock, and V. S. Bryantsev, J. Phys. Chem. B 119, 3567-3576, (2015), (b) N. Mehio, B. Williamson, Y. Oyola, R. T. Mayes, C. Janke, S. Brown, and S. Dai, Ind. Eng. Chem. Res. 55, $4217-$ 4223, (2016)

29. (a) X. Guo, Y. Wang, C.Li, P. Huai \& G. Wu, Mol. Phys. 113, 1327-1336, (2015), (b) J. Xiong, S. Hu, Y. Liu, J. Yu, H. Yu, L. Xie, J. Wen, and X Wang, ACS Sustainable Chem. Eng. 5, 1924-1930, (2017)

30. O. Nibel, M. Bon, M. L. Agiorgousis, T. Laino, L. Gubler, and T. J. Schmidt, J. Phys. Chem. C 121, 6436-6445, (2017)

31. S. Lin, , L. Yang, Tetrahedron Lett. 46, 4315, (2005)

32. B. G. Zaleta, M. T. R. Silva, A. Guti'errez, E. G. Vergara, M. G. Rodr' 1 guez, A. R. Hern'andez, Spectrochimic. Act. Part A 64, 1002, (2006)

33. F. Eloy F, R. Lenaers, Chem. Rev. 62, 155, (1962)

34. A. H. Amrallah, N. A. Abdalla, E. Y. El-Haty, J Chin. Chem. Soc. 53, 697, (2006) 